\section{VOLUNTEERS NEEDED FOR CRISIS AT CHRISTMAS}

Crisis is looking for qualified dentists, dental nurses and dental hygienists to help run the Dental Service at Crisis At Christmas this year, to build on the success of 2009 when over 260 patients received dental treatment. Shifts run from 9am to 5.30pm from 29 December with a minimum of two shifts. Senior dental nurse Bianca Payne volunteered for Crisis At

'Admittedly, I was a little daunted by the idea of coming face to face with these unfortunate people whom we see every day across London, and who seem largely ignored by our society.

'When I turned up on that first chilly morning, I was immediately affected by the warmth of the place. Friday 24 December to Wednesday Christmas in 2008:

It was buzzing! There were people everywhere - holding steaming cups of tea and coffee, engrossed in wholesome conversations and having a good laugh. I couldn't tell the difference between the guests and the volunteers. It seemed that this was an old meeting place for good friends.

'The dentistry was carried out in a couple of fully equipped vans which weren't much smaller than some of the surgeries I've worked in around London. Furthermore, we had heating and a steady supply of chocolate to keep up our energy levels!

To find out how you can volunteer email ccvolunteering@crisis.org.uk apply online at www.crisis.org.uk/ volunteering or telephone 08448928980.

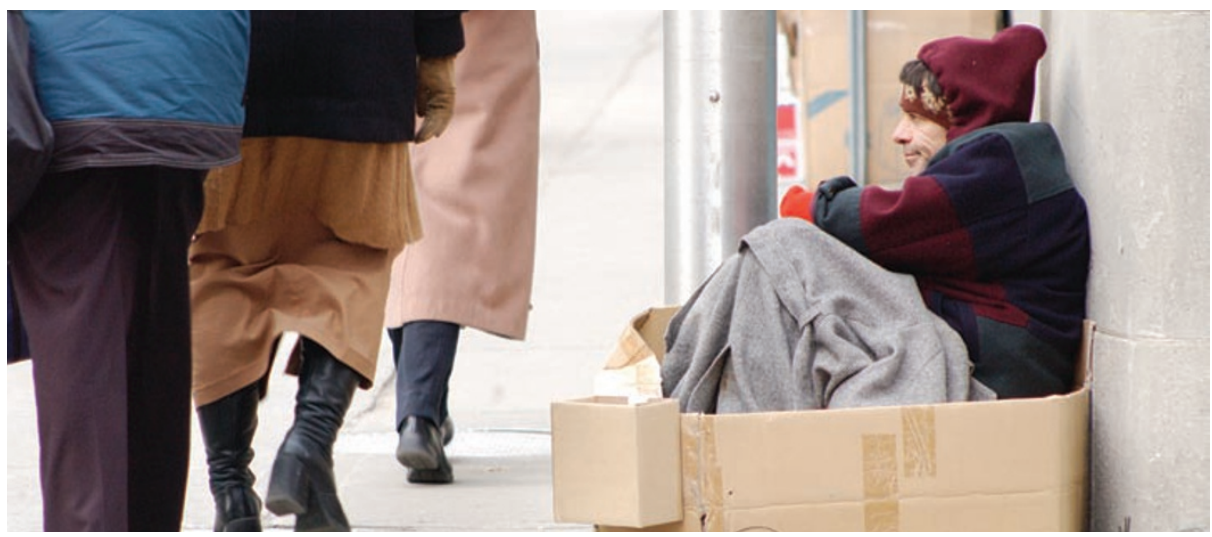

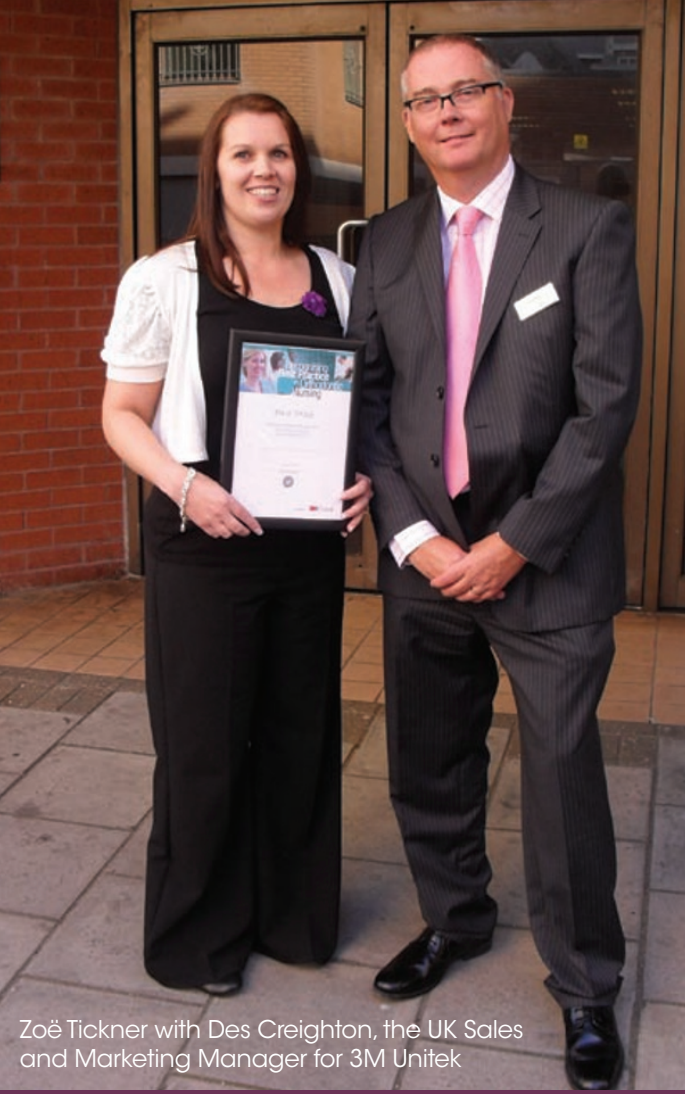

\section{ZOË CONQUERS THE COMPETITION}

Practice manager and group nursing manager Mrs Zoë Tickner of Total Orthodontics

Horsham took first place and won $£ 300$ in a National Orthodontic Nursing Competition at the British Orthodontic Conference in

Brighton in September.

The Orthodontic Nursing Award, which is sponsored by $3 \mathrm{M}$ Unitek, aims to recognise best practice in orthodontic nursing. To reach the final Zoë was asked to submit an outline for a proposed presentation on a topic of her choice. Five finalists were then selected to present at the British Orthodontic Conference. Zoës chosen topic was 'An introduction to HTM 01-05 decontamination guidance in orthodontic practice', where she outlined the required standards in decontamination for orthodontic practices and how to achieve best practice.

'I could not believe it when my name was read out as the first place winner!' said Zoë. 'I was so nervous and the competition was tough. I still cannot believe it and am still beaming from ear to ear!' opportunity to improve their presentation skills through the process of reflection and peer review. Stage two modules also increased the students' clinical knowledge, initiative and confidence which in turn will benefit their professional relationships.

Nicky and fellow undergraduate Sue

Bagnall have even expanded their career opportunities by starting their own business, www.cpd4dentalnurses.co.ul.

The BSc in Primary Dental Care students will graduate in June 2011. For more information on the course, contact Programme Director Debbie Reed on d.reed@kent.ac.uk or telephone 016342020919. 